\title{
Avaliação escolar antes e durante a pandemia: como os alunos enxergam esse
}

\section{momento}

\author{
School evaluation before and during the pandemic: how students see this moment
}

Evaluación escolar antes y durante la pandemia: como ven los estudiantes este momento

Recebido: 30/11/2021 | Revisado: 05/12/2021 | Aceito: 10/12/2021 | Publicado: 20/12/2021

Gleiciane de Jesus Silva Neiva

ORCID: https://orcid.org/0000-0002-4769-5693

Instituto Federal de Educação, Ciência e Tecnologia do Triângulo Mineiro, Brasil

E-mail: gleicianeneiva@gmail.com

Ângelo Gomes de Melo

ORCID: https://orcid.org/0000-0001-5376-5507

Instituto Federal de Educação, Ciência e Tecnologia do Triângulo Mineiro, Brasil

E-mail: angelo@iftm.edu.br

\begin{abstract}
Resumo
A pesquisa, de caráter qualiquantitativa, tem o objetivo de apresentar e discutir sobre como os alunos de uma escola estadual situada em Minas Gerais enxergam os processos de avaliação escolar, seus sentimentos em relação ao assunto, quais foram os tipos de avaliação que mais fizeram durante a sua vida e como os afetou. Também apresentar a forma que a pandemia de COVID-19 afetou as relações escolares e como os alunos foram prejudicados nesse momento. Mesmo com todos os obstáculos enfrentados devido a pandemia, esta pesquisa só foi possível utilizando de Tecnologias de Informação e Comunicação (TICs). Neste trabalho foi utilizado a plataforma de troca de mensagens WhatsApp para conversar e dar informação aos participantes e um questionário que foi respondido pela plataforma Google Forms pelos alunos participantes. Os resultados mostram os medos e anseios dos alunos, as suas necessidades e a importância que dão para as avaliações escolares. Evidencia a importância do professor e da família nos estudos durante o ensino remoto, como o apoio foi importante nesse momento. Os resultados mostram os futuros desafios da vida escolar e como pode-se a partir do olhar do aluno perceber as novas demandas da nova geração.
\end{abstract}

Palavras-chave: Avaliação escolar; Educação; Alunos; Pandemia; Ensino.

\begin{abstract}
The purpose of this qualitative quali research is to present and discuss how students from a state school located in Minas Gerais see the school evaluation processes, their feelings about the subject, what types of evaluation they did most during their life, and how it affected them. It also shows how the COVID-19 pandemic affected school relationships and how were harming the students at that time. Even with all the obstacles faced due to the pandemic, this research was only possible using Information and Communication Technologies (ICTs). And in this work, a message exchange platform called WhatsApp was used to talk and provide information to the participants also, a questionnaire was answered by the students through the Google Forms platform. The results showed the students' fears and anxieties, their necessity and the importance they give to school evaluations. It shows the importance of the teacher and family in studies during remote education, as support was important at the time. The results show the future challenges of school life and how we can, from the student's perspective, perceive the demands of the new generation.
\end{abstract}

Keywords: School evaluation; Education; Students; Pandemic; Teaching.

\section{Resumen}

La investigación cualitativa y cuantitativa tiene como objetivo presentar y discutir cómo los estudiantes de una escuela estatal ubicada en Minas Gerais ven los procesos de evaluación escolar, sus sentimientos sobre el tema, qué tipos de evaluación hicieron más durante su vida y cómo les afectó. También presente cómo la pandemia de COVID19 afectó las relaciones escolares y cómo los estudiantes sufrieron daños en ese momento. Incluso con todos los obstáculos enfrentados debido a la pandemia, esta investigación solo fue posible utilizando las Tecnologías de la Información y la Comunicación (TIC). En este trabajo se utilizó la plataforma de intercambio de mensajes de WhatsApp para charlar y informar a los participantes y un cuestionario que fue respondido por la plataforma Google Forms por los estudiantes participantes. Los resultados muestran los miedos y ansiedades de los estudiantes, sus necesidades y la importancia que le dan a las evaluaciones escolares. Destaca la importancia del profesor y la familia en los estudios durante la educación a distancia, ya que el apoyo era importante en ese momento. Los resultados 
muestran los desafíos futuros de la vida escolar y cómo, desde el punto de vista del alumno, es posible percibir las nuevas demandas de la nueva generación.

Palabras clave: Evaluación escolar; Educación; Estudiantes; Pandemia; Enseñanza.

\section{Introdução}

Avaliar é um processo vivo e importante para o percurso escolar e saber bem os objetivos que se precisam alcançar com essa ferramenta é importante. Neste artigo será discutido como os alunos de uma escola Estadual de Minas Gerais enxergam os processos avaliativos, como lidam com esse momento e a forma que o momento pandêmico está afetando as suas relações com a escola.

Devido a avaliação escolar ser um processo bastante complexo e que envolve várias pessoas, Libâneo (2006, p. 195) coloca que "A avaliação é uma tarefa complexa que não se resume à realização de provas e atribuição de notas". Segundo Furlan (2007), a avaliação escolar somente tem sentido se for aplicada com o propósito de conhecer um pouco mais a respeito do aluno e de reunir informações a fim de que o ensino escolar ocorra de maneira bem próxima da realidade e de forma contextualizada. Dado esses fatores, a avaliação permeia todos os processos escolares, iniciando-se pelo planejamento, conhecimento do aluno, resposta e a reavaliação dos currículos.

Compreender como o processo de avaliação vem acontecendo e verificar como os alunos entendem o processo é uma situação bem importante no ensino. A avaliação é algo do ser humano, o qual está a todo o momento se avaliando e reavaliando as ações a serem tomadas. Morais e Moura nos dizem que:

O pressuposto fundamental é que a avaliação constitui-se em uma ação inerente à atividade humana, visto que o homem, ao estabelecer, intencionalmente, a finalidade para sua atividade, analisa as condições de realização antecipadamente e durante o processo, se necessário, faz modificações para que o resultado final atinja o objetivo idealizado de modo a satisfazer suas necessidades (Morais \& Moura, 2009, p. 98).

Assim percebe-se que avaliar não é somente um ato feito dentro de escolas, mas algo que está presente na vida e que precisa ser entendida como um meio de se ter objetivos, metas e resultados, visando que projetos e planejamentos alcancem seus objetivos ou precisem ser revistos. Segundo Libâneo (2006, p. 199) "O entendimento correto da avaliação consiste em considerar a relação mútua entre os aspectos quantitativos e qualitativos".

A Base Nacional Comum Curricular (BNCC) propõe que reconhecer o contexto dos antecedentes, ser participativo, ser crítico e analítico vai muito mais do que armazenar conhecimentos (Brasil, 2017). Ao reconhecer essas características, coloca-se o aluno no centro da busca pelo entendimento de suas opiniões e conhecimentos.

Atualmente se vive um momento em que a educação está se remodelando e buscando novas formas de ensinar os alunos em suas casas. No início de 2020, a Organização Mundial da Saúde (OMS) elevou o estado de contaminação pela COVID-19 a uma pandemia. No Brasil, tal decisão, levou o Governo Federal a decretar estado de calamidade pública através do decreto legislativo $n^{\circ} 6$ (2020), a partir desse momento, muitas medidas para conter o avanço da doença no país foram tomadas, dentre elas a suspenção de aulas presenciais e o início do ensino remoto.

A partir desse cenário e de experiências dentro do sistema educacional durante o curso de Licenciatura em Matemática, iniciou-se o interesse por entender melhor como os alunos enxergam as avaliações escolares antes e durante a pandemia de COVID-19 e como todo esse novo cenário da educação afetou as suas relações com a escola.

\section{Referencial Teórico}

No decorrer dos anos, os currículos escolares sofreram várias alterações com o intuito de se adaptarem as mudanças da sociedade, mas para Perrenoud e Thurler (2009, p. 17) “as reformas escolares fracassam, os novos programas não são 
aplicados, belas idéias como os métodos ativos, o construtivismo, a avaliação formativa ou a pedagogia diferenciada são pregadas, porém nunca praticadas".

Luckesi (2005) diz que hoje o que se chama de avaliação de aprendizagem, muito pouco parece com uma avaliação e que provas e exames são mais utilizados do que a própria avaliação. Para Hoffmann (1993), "a avaliação é uma reflexão permanente sobre a realidade, e acompanhamento, passo a passo, do educando, na sua trajetória de construção de conhecimento".

Segundo Luckesi (2014, p .17), as notas escolares que têm sido realizadas nas escolas, não colaboram para concretizar "o sonho, a esperança e o desejo da democratização do ensino" e que a qualidade integral do aluno não pode ser obtida pela média ou algum outro atributo que não corresponda a uma "aprendizagem satisfatória por parte do educando dos conteúdos que deveria aprender" (Luckesi, 2014, p. 10).

Assim, Luckesi classifica provas e exames como algo que:

[...] têm por finalidade, no caso da aprendizagem escolar, verificar o nível de desempenho do educando em determinado conteúdo [...] e classificá-lo em termos de aprovação/reprovação [...]. Desse modo, provas/exames separam os "eleitos" dos "não-eleitos". Assim sendo, essa prática exclui uma parte dos alunos e admite, como "aceitos", uma outra" (Luckesi, 2005. p. 169).

Segundo Perrenoud (2012, p. 25) "as competências não podem ser construídas sem avaliação, porém esta não pode assumir a forma de testes com papel e lápis ou dos exames universitários clássicos". Libâneo (2006) ainda ressalta que ao atribuirmos notas aos alunos estamos com propósito de controlá-los e classificá-los e não temos nesse momento uma função educativa. Assim percebe-se que atualmente avaliar no sentido de classificar alunos não beneficia em nada o processo de ensino e aprendizagem. Pavanello e Nogueira (2006, p. 36) relatam que:

[...] a avaliação tem, tradicionalmente, se centrado nos conhecimentos específicos e na contagem de erros. É uma avaliação somativa, que não só seleciona os estudantes, mas os compara entre si e os destina a um determinado lugar numérico em função das notas obtidas.

Morais e Moura (2009) reforça-se a ideia da significação da avaliação, como atividade de ensino e aprendizagem, que deve ser uma orientação e indicação do conhecimento adquirido, para analisar e sintetizar as atividades do professor e do aluno. Logo, entender o significado da avaliação dentro do processo de ensino e aprendizagem, torna-se importante para os currículos e planejamentos dos professores. De acordo com Luckesi (2011) "o professor, na medida em que está atento ao andamento dos seus alunos, poderá, através da avaliação da aprendizagem, verificar o quanto o seu trabalho está sendo eficiente e que desvios está tendo" (Luckesi, 2011, p. 117).

Zabala (1998, p. 195) salienta que "Basicamente, a avaliação é considerada como instrumento sancionador e qualificador, em que o sujeito da avaliação é o aluno e somente o aluno, e o objeto da avaliação são as aprendizagens realizadas segundo certos objetivos mínimos para todos". Outro ponto importante citado por Pavanello e Nogueira é:

Se há um ponto de convergência nos estudos sobre a avaliação escolar é o de que ela é essencial à prática educativa e indissociável desta, uma vez que é por meio dela que o professor pode acompanhar se o progresso de seus alunos está ocorrendo de acordo com suas expectativas ou se há necessidade de repensar sua ação pedagógica. Quanto ao aluno, a avaliação permite que ele saiba como está seu desempenho do ponto de vista do professor, bem como se existem lacunas no seu aprendizado às quais ele precisa estar atento (Pavanello \& Nogueira, 2006, p. 30).

Então, Zabala (1998), Luckesi (2005), Libâneo (2006), Pavanello e Nogueira (2006), Morais e Moura (2009) entendem que o processo avaliativo é importante e precisa ser processado, tanto pelo professor quanto pelo aluno. Entender 
como cada um desses componentes do sistema educacional fazem uso do sistema avaliativo, torna-se importante para direcionar esforços e conhecimento pessoal de todos.

Libâneo (1983) afirma que uma grande parte dos professores mantem uma base prática de suas ações pedagógicas que se fizeram senso comum, que vieram de quando estavam na escola ou advindas de colegas com mais tempo de carreira, práticas essas que possuem pré-suposições implícitas da vida escolar. Esse conhecimento mesmo que carregado de experiência, pode no decorrer da vida profissional acarretar em práticas e ações pouco efetivas.

Assim Luckesi (2005) nos diz que a avaliação vem para auxiliar o professor e o aluno no crescimento dentro da educação conjunta na escola e também na sociedade. Reforçando assim que o entendimento da avaliação permeia em todos os sentidos do caminho escolar. De acordo com Perrenoud e Thurler (2009, p. 25) "a avaliação das competências deve ser formativa, passar por uma co-análise do trabalho dos estudantes e pela regulação de seus investimentos mais do que pelas notas ou classificações".

Recentemente, no ano de 2017, o Brasil começa uma nova faze na educação com a aprovação da Base Nacional Comum Curricular (BNCC) que cria as competências gerais para ensino e aprendizagem dos alunos, sendo um grande marco na educação brasileira. A BNCC

[...] integra a política nacional da Educação Básica e vai contribuir para o alinhamento de outras políticas e ações, em âmbito federal, estadual e municipal, referentes à formação de professores, à avaliação, à elaboração de conteúdos educacionais e aos critérios para a oferta de infraestrutura adequada para o pleno desenvolvimento da educação (MEC, 2017, p. 8).

Não só como políticas e ações em todo território nacional na educação, a BNCC vem contribuir para que todo aluno tenham a capacidade de fazer, saber e como saber fazer (MEC, 2017). A avaliação por meio de seus instrumentos pode ajudar a descobrir quais as aptidões dos alunos e o que pode ser feito para potencializar as habilidades e saberes.

Assim a BNCC vem com o compromisso de promover uma educação integral, a fim de que os estudantes possam se desenvolver e que sejam acolhidos amplamente sem nenhum tipo de diferenças (MEC, 2017). A partir disso, podemos iniciar a nossa busca por entender os alunos, compartilhar conhecimentos e buscar modelar uma educação mais acessível a todos.

Dentro dessa temática de integração na educação, Pestana e Coqui (2021) relatam em seu trabalho que hoje o processo avaliativo é um grande desafio na educação; uma vez que o processo mostra as fragilidades do sistema educacional na reprovação e evasão escolar, apesar de ser um instrumento para medir a competência da prática do professor. Para Luckesi (2011) o processo avaliativo é reflexo de uma questão histórico-cultural agregadas aos exames frequentemente realizados no século passado.

À medida que se entende quais são os desafios e os novos rumos da avaliação escolar, Fachineto et al. (2020) corroboram com a ideia de que a avaliação não é para simplesmente atribuir aos alunos notas ou aprovar ou reprovar em determinada disciplina. Certamente, as novas relações escolares podem mudar a visão do aluno em relação a essas atividades.

Destaca-se a existência de três modalidades na avaliação e a partir delas os seus instrumentos que podem ser aplicados de diversas formas nas escolas. A avaliação, segundo Rampazzo e Jesus (2011) pode possuir três modalidades, conforme a necessidade do professor. A primeira delas é a avaliação diagnóstica que nos indica como está o aluno no início de algum ciclo, a qual não se prende a somente ao início do ano letivo. A segunda é a avaliação formativa que estabelece a situação do professor e do aluno durante o processo escolar, visando quais as mudanças serão necessárias para uma melhor aprendizagem. A avaliação somativa aparece como a terceira modalidade, a qual coloca o professor e aluno no final de todo o processo, sendo realizada para atestar a capacidade e resultados alcançados. A avaliação somativa também é muito usada em sua forma 
classificatória. Percebe-se que cada modalidade possui características únicas, que possibilitam tanto ao professor quanto ao aluno obter respostas durante o ensino e aprendizagem.

Percebe-se que além do processo avaliativo incluir saber o que o aluno aprendeu ou ainda não aprendeu, ele também deve possibilitar a inclusão de experiências anteriores do aluno no ensino realizado em sala de aula (Rampazzo \& Jesus, 2011). Para Hoffmann (2001, p. 47) todos os alunos estão a todo momento em crescimento, porém em ritmos diferentes, seguindo passos únicos e próprios. "O olhar do professor precisará abranger a diversidade de traçados, provocando-os a progredir sempre".

Do mesmo modo a BNCC destaca outra grande importância de valorizar o processo educativo e suas formas de ensinar e avaliar um aluno e as necessidades para a sociedade dizendo que "A sociedade contemporânea impõe um olhar inovador e inclusivo a questões centrais do processo educativo: o que aprender, para que aprender, como ensinar, como promover redes de aprendizagem colaborativa e como avaliar o aprendizado" (MEC, 2017 p. 14).

Com os novos desafios devido à pandemia de COVID-19, o Conselho Nacional de Educação no parecer n 19 de 8 de dezembro de 2020, na seção 5 artigo 14, coloca as atividades não presenciais, aquelas realizadas por meios tecnológicos e outros sistemas, que garantam a continuação das atividades durante o período restritivo de presença física. O Capítulo 4 artigo 27 da mesma resolução diz queas avaliações devem ser focadas nos objetivos de aprendizagem e no desenvolvimento de competências essenciais (Conselho Nacional de Educação, 2020a).

\section{Metodologia}

Essa pesquisa se caracteriza como uma pesquisa de natureza qualiquantitativa e iniciou-se com a curiosidade de saber a opinião de alguns alunos da terceira série do Ensino Médio de uma escola da rede Estadual de ensino de Minas Gerais. Todo o processo de pesquisa com os alunos ocorreu no mês de junho de 2021. Dentro da pesquisa buscou-se saber alguns pontos: i) entender como os alunos veem os processos avaliativos; ii) saber se o momento da avaliação é algo justo ou os deixa desconfortáveis; iii) saber quais tipos de avaliação foram realizados com maior frequência pelos alunos durante a vida escolar; iv) se os resultados que recebem de seus professores interferem em seus estudos e v) saber como as aulas remotas interferiram no cotidiano dos alunos, a relação com a família e os desafios.

Um questionário foi aplicado para alunos de três turmas do terceiro ano do Ensino Médio, atingindo14 estudantes com idades de 16 a 18 anos que se interessaram responder o questionário. Apesar de existir muitos alunos nas turmas, a baixa participação na pesquisa se deu devido às aulas estarem acontecendo de forma remota. Muitos dos alunos que foram convidados para estarem participando estavam trabalhando ou não tiveram o interesse em participar, pois devido a pandemia COVID-19 alegaram estar cansados.

Para a elaboração dessa pesquisa, primeiro envolveu um estudo de 6 artigos selecionados através da ferramenta de busca Google Scholar, utilizando os seguintes descritores: i) Avaliação em Matemática: foi analisado em todo o texto e não foi colocado um período. Avaliaram-se os 10 primeiros artigos por ordem de relevância; ii) Avaliação escolar pandemia: foi analisado em todo o texto nos anos de 2020 e 2021. (Examinou-se os 10 primeiros artigos por ordem de relevância e iii) Avaliação escolar alunos: foi analisado somente no título entre os anos de 2020 e 2021. Alguns livros e artigos usados vieram de buscas na biblioteca, por meio de autores mais discutidos durante o curso de Licenciatura em Matemática artigos que foram utilizados pelo professor da disciplina de práticas pedagógicas e indicados pelo orientador do trabalho.

A construção do questionário que foi aplicado aos alunos se deu em conjunto com o professor orientador deste trabalho e com a professora que ministra a disciplina de Trabalho de Conclusão de Curso (TCC); além das pesquisas bibliográficas sobre os assuntos selecionados que foram abordados. 
Inicialmente foi conversado com a diretora da escola a respeito da aplicação do questionário para os alunos, com a finalidade de obter a sua autorização. Após esse momento, foi usado um grupo do aplicativo de troca de mensagens, o WhatsApp, em que os alunos recebiam da escola avisos das atividades. Logo após foi enviado aos alunos uma mensagem explicando e convidando-os a participarem da pesquisa. Aqueles que se interessaram em participar, acessaram por meio de um link um grupo de WhatsApp, onde foram passadas mais informações sobre os procedimentos por meio de ligações e mensagens de professores.

Posteriormente os Termos de Consentimento Livre e Esclarecido (TCLE) e o Termo de Assentimento Livre e Esclarecido (TALE) foram levados aos alunos que aceitaram o convite para que pais e alunos assinassem sem a necessidade de saírem de suas casas. Essa ação se deu visando não causar nenhum tipo de aglomeração ou proporcionar algum risco a saúde de algum participante e seus familiares. Após assinatura dos termos, foi enviado a cada aluno um link pelo WhatsApp para acessarem o questionário pela plataforma Google Forms. As respostas do questionário foram tabuladas, analisadas e transcritas para manter o anonimato dos participantes. Veja a transcrição do questionário respondido pelos alunos na Figura 1. 
Figura 1: Transcrição do questionário respondido pelos alunos.

$\begin{array}{llllll}\text { 1- Idade } & & & & \\ \text { () } 15 & \text { () } 16 & \text { ()17 } & \text { ()18 } & \text { ()19 } & \text { ( } \\ \text { 2-Você sabe o que é avaliaçào? } & & & & \\ \text { () Nada } & \text { ()Pouco } & \text { ()Bastante } & & \text { ()Muito }\end{array}$

3- Qual(is) dos seguintes itens a segui você considera se uma modalidade de avaliação eficaz? (você poderá marcar mais de uma opção)

()Avaliação diagnostica ()Avaliação formativa $\quad$ ()Avaliação somativa

4- Por quais instrumentos de avaliação abaixo você já foi avaliado? Classifique de acordo com o uso na sua vida escolar.

Nunca utilizado Pouco utilizado
utilizado

\begin{tabular}{|c|c|c|c|}
\hline Prova objetiva & ( ) & ( ) & ( ) \\
\hline Prova discursiva & ( ) & ( ) & $($ ) \\
\hline Prova oral & ( ) & () & ( ) \\
\hline Mapa conceitual & ( ) & () & () \\
\hline Relatório & ( ) & ( ) & ( ) \\
\hline Estudo dirigido & () & () & () \\
\hline Portfolio & ( ) & ( ) & () \\
\hline Seminário & $($ ) & () & () \\
\hline
\end{tabular}

5- Você acha que as avaliações escolares são justas?

( )Nada justas ( )Pouco justas ( ) Muito justas

6- Você sente que seu conhecimento apresentado durante as avaliações escolares é valorizado pelo professor?

$\begin{array}{lll}\text { ( ) Nunca valorizado } & \text { ( )Pouco valorizado } & \text { ( ) Muito valorizado }\end{array}$ 
7- Você se sente em momentos de avaliação escolar?

( )Não me sinto a vontade ( )Me sinto pouco a vontade ( ) Me sinto a vontade

8- Você estuda para as avaliações escolares?

( ) Sim ( ) Não ( ) As vezes $\quad$ ( ) Somente para algumas

9-Quanto tempo você dedica aos estudos para a realização de uma avaliação escolar?

( )Menos de uma hora $\quad$ ( )Entre uma e três horas por semana

( )Entre quatro e seis horas por semana ( )Entre sete a nove horas por semana

( )Mais de dez horas

10- Os resultados obtidos nas avaliações interferem nos seus estudos?

( )Não interferem ( )Pouco interferem ( )Interferem

11- Os professores normalmente fazem a correção das avaliações escolares?

( ) Sempre fazem as correções ( )As vezes fazem as correções

( ) Sempre fazem as correções

12- Você considera a correção das avaliações escolares importante?

( )Nada importante ( )Pouco importante ( )Muito importante

13- No seu entendimento, as avaliações que você realizou durante a vida escolar contribuíram para o seu aprendizado?

( )Não contribuíram em nada ( )Pouco contribuíram $\quad$ ( )Contribuíram

14 - Durante a vida escolar, qual tipo de avaliação você mais realizou?

15- Qual tipo de avaliação que contribuiu com sua aprendizagem durante todo o seu percurso escolar? 
16- Durante o período de estudos remotos, devido a pandemia de COVID-19, as avaliações escolares o ajudaram em seu aprendizado?
( )Não ajudaram
( )Pouco ajudaram
( )Ajudaram

17- Você sente que no ensino remoto você foi prejudicado de alguma forma?
( )Não fui prejudicado
( )Fui pouco prejudicado
( )Fui muito prejudicado

18- Durante o ensino remoto você fez ou az suas avaliações escolares realizando algum tipo de consulta?

$\begin{array}{cccc} & \text { Nada consultei } & \text { Pouco consultei } & \text { Consultei } \\ \text { Livro físico } & (\text { ) } & (\text { ) } & (\text { ) } \\ \text { Colega } & (\text { ) } & (\text { ) } & (\text { ) } \\ \text { Internet } & (\text { ) } & (\text { ) } & \text { ( ) }\end{array}$

19- A presença do professor no ensino do conteúdo, faz diferença para o seu aprendizado?
( )Não faz diferença
( )Pouco faz diferença
( )Faz diferença

20- Sua família de alguma forma contribuiu para seus estudos em casa?
( ) Nada contribuiu
( )Pouco contribuiu
( )Muito Contribuiu

21- Sua família auxilia durante os estudos e avaliações?
( )Não auxilia em nada
( )Pouco auxilia
( )Muito auxilia

22- Durante as aulas remotas, em algum momento você teve que deixar de estar se dedicando aos estudos para ajudar a família em situações que antes não ajudava normalmente?

( ) Sim ( )Não

23- Você acredita que o ensino remoto pode ser direcionado de forma diferente do que está sendo aplicado hoje em sua escola?
( ) $\operatorname{Sim}$
( )Não

24- Se você respondeu sim na questão anterior, de que forma, na sua opinião, o ensino remoto pode ser feito?

Fonte: Próprios autores (2021).

\section{Resultados e Discussão}

O questionário composto de 22 questões de múltipla escolha e três questões discursivas foi respondido por alunos com idades de 16 a 18 anos que cursam o $3^{\circ}$ ano no Ensino Médio. A primeira parte das perguntas foi focada nas relações e 
entendimentos dos alunos com a avaliação escolar e a segunda parte sobre como a pandemia afetou suas relações com a escola. Então para um melhor entendimento a discussão é feita em duas partes.

\subsection{Avaliação escolar}

A primeira pergunta feita a eles foi se eles sabiam o que era avaliação e dentre as respostas obtidas $14,3 \%$ dos alunos disseram que sabem pouco, $50 \%$ sabem bastante e $37,7 \%$ sabem muito sobre avaliação.

Em seguida dentre as três modalidades de avaliação que foram consideradas para a pesquisa foi perguntado qual ou quais os alunos consideravam uma modalidade eficaz. Verificou-se que $85,7 \%$ dos alunos assinalaram a avaliação diagnóstica como uma modalidade eficaz no ensino, $71,4 \%$ assinalou a avaliação somativa eficaz e $42,9 \%$ assinalaram a avaliação formativa como método eficaz. Os dados apurados ultrapassaram 100\%, uma vez que os alunos poderiam escolher mais de uma modalidade.

Os alunos ao considerarem avaliação diagnóstica a modalidade mias eficaz pode se dar ao fato de ser o tipo de avaliação mais realizada por grande parte dos alunos que responderam ao questionário evidenciando assim essa influência. Constatou-se que 57\% dos alunos fizeram em sua vida escolar mais avaliações diagnósticas, $29 \%$ dos alunos disseram que realizaram provas objetivas e discursivas e 7\% dos alunos indicaram avaliação somativa e avaliação formativa em ambos os casos como sendo a mais realizada por eles.

Diante dos resultados obtidos pode-se perceber que os alunos dentro do seu repertório escolar realizaram mais avaliações diagnósticas. Essas avaliações eram usadas pelas escolas para saber qual o nível de conhecimento do aluno e quais medidas deveriam ser tomadas. Portanto, como Morais e Moura (2009) nos dizem, avaliar é intrínseco do planejamento e andamento da atividade, considerando que se realiza no seguimento do estudo e síntese na relação entre a atividade proposta pelo professor e a executada pelo aluno. Desse modo percebe-se que a escola sempre está buscando de alguma forma saber como está o aluno e seus conhecimentos.

Em virtude da existência de vários instrumentos de avaliação, outra informação que se buscou, foi saber quais métodos avaliativos os alunos mais fizeram durante sua vida escolar. Desta forma eles classificaram os seguintes métodos conforme consta na Tabela 1 a seguir:

Tabela 1: Instrumentos de avaliação e sua utilização segundo os alunos.

\begin{tabular}{|cccccc}
\hline Métodos de avaliação & Nunca utilizado & Pouco utilizado & Bastante utilizado & Muito utilizado & Total \\
\hline Prova objetiva & 3 & 2 & 4 & 5 & 14 \\
Prova discursiva & 4 & 4 & 4 & 2 & 14 \\
Prova oral & 4 & 9 & 1 & 0 & 14 \\
Mapa conceitual & 5 & 7 & 2 & 0 & 14 \\
\hline Métodos de avaliação & Nunca utilizado & Pouco utilizado & Bastante utilizado & Muito utilizado & Total \\
\hline Relatório & 2 & 7 & 5 & 0 & 14 \\
Estudo dirigido & 5 & 5 & 3 & 1 & 14 \\
Portfólio & 10 & 2 & 2 & 0 & 14 \\
Seminário & 7 & 5 & 2 & 0 & 14 \\
\hline
\end{tabular}

Fonte: Elaboração própria.

A tabela apresenta a prova objetiva sendo bastante ou muito utilizada por nove alunos, o que representa $65 \%$ do total. As provas discursivas e orais foram consideradas pouco ou nunca utilizadas por $57 \%$ e $93 \%$ dos alunos respectivamente. Mostrando que não reconhecem esses métodos como sendo mais usados pelos professores. Relatório, mapa conceitual e estudo dirigido apresentam usos esporádicos, variando entre pouco usados e bastante utilizados, com uma média de nove alunos entre 
essas duas classificações. Seminário e portfólio em ambos os casos foram considerados por $86 \%$ dos alunos como pouco ou nunca utilizados.

Libâneo (2006) diz que é comum que tomemos a avaliação somente como um ato de aplicar provas, consequentemente atribuir uma nota e reduzir a cobrança ao que o aluno memorizou. Deste modo as atividades que demandam criatividade ou independência do aluno para sua realização, como por exemplo seminários e relatórios, são pouco usados nas escolas. Atividades que demandam esforço tanto do aluno quanto do professor, como o portfólio, se tornam menos usado ainda.

Os alunos ao responderem se acham ou não as avaliações escolares justas, 50\% deles acham que são justas enquanto os outros 50\% acham pouco ou nada justas. Também do mesmo modo perguntados se acham que seu conhecimento é valorizado pelos professores, $50 \%$ acha que seu conhecimento é valorizado enquanto os outros $50 \%$ acha que seu conhecimento é pouco ou nunca valorizado por eles. Percebe-se então uma dualidade de opiniões em relação a esses temas, uma metade se considera desvalorizada e injustiçada pelas avaliações enquanto outra que sente seu conhecimento valorizado e justo a forma das avaliações.

Vendo esses resultados percebe-se que avaliar envolve muitas variáveis e que muitas vezes não será do agrado de todos. Libâneo (2006, p. 203) ao dizer que "A avaliação escolar, portanto, envolve a objetividade e a subjetividade, tanto em relação ao professor como aos alunos" fica evidente que essas dualidades de opinião possam aparecer no decorrer do ensino.

Apesar de 57,1\% dos alunos afirmarem que se sentem pouco ou nada à vontade nesse momento, ao serem questionados sobre a importância da avaliação, todos eles consideram que as avaliações escolares são muito importantes. Percebe-se que apesar de todos os problemas que enfrentam, os alunos consideram esse momento com algo importante na vida escolar. A avaliação para $64,3 \%$ dos alunos contribui de alguma forma para o seu aprendizado e para outros $35,7 \%$ pouco contribuíram ou em nada contribuíram para o aprendizado.

Com a finalidade de também entender se estudam para as avaliações e quanto tempo dedicavam, obteve-se que 42,9\% dos alunos estudam para as avaliações, $21,4 \%$ às vezes estudam enquanto $35,7 \%$ estudam somente para algumas matérias. Em relação ao tempo dedicados a esses estudos, $28,6 \%$ estudam menos de uma hora por semana, $50 \%$ dedicam de uma a três horas durante a semana enquanto $21,4 \%$ de quatro a seis horas.

Da mesma forma foram perguntados se os professores fazem a correção das avaliações. Para $71,4 \%$ dos alunos seus professores sempre fazem as correções de suas avaliações, evidenciando que os professores retornam aos seus alunos seus erros e acertos contribuindo para o seu crescimento escolar e de suas estratégias. Com esse retorno do professor, 42,9\% dos alunos afirmam que os resultados obtidos interferem em seus estudos, para outros $42,9 \%$ pouco interferem e para $14,3 \%$ nada interferem em suas estratégias.

Os participantes também responderam qual tipo de avaliação mais contribuiu para a sua aprendizagem. Dentre as respostas, a avaliação diagnóstica apareceu novamente como sendo a avaliação que mais contribuiu para cinco alunos. Em seguida, relatório juntamente com prova discursivo/escrita e apresentação/seminário foram elencados por dois alunos em cada modalidade. Essas atividades demandam criatividade e liberdade do aluno estar criando suas respostas e ações sendo um tipo de avaliação mais subjetiva. As avaliações formativas e provas objetivas foram colocadas por um respectivamente.

Os simulados e provas orais apareceram como avaliações que contribuíram para o ensino juntamente com outras respostas. Apenas um aluno respondeu que nenhum tipo de avaliação contribuiu para a sua aprendizagem durante o seu percurso escolar.

Finalizando a parte de avaliações escolares, os alunos classificaram seu desempenho nas avaliações em uma métrica de um a cinco, em que um é nada bom e cinco é muito bom. Para 71,4\% dos alunos seu desempenho esta na média, de 2 a 4, o que corresponde a 10 dos 14 participantes. Percebe-se que dentro do universo de avaliação, em nenhum momento os alunos se 
colocam em grandes patamares de estudo, desempenho ou vontades mesmo que nas alternativas das perguntas tivessem essa opção. Por esse motivo a BNCC (MEC, 2017) quando diz para que sejam aplicadas metodologias e estratégias didáticopedagógicas variadas para o trabalho são para suprir as diferentes necessidades dos alunos e suas habilidades para valorizar os seus conhecimentos, sua cultura e para a socialização.

Então quando Zabala (1998, p. 200) nos diz que "A fim de validar as atividades realizadas, conhecer a situação de cada aluno e poder tomar as medidas educativas pertinentes, haverá que sistematizar o conhecimento do progresso seguido" entende-se que devemos conhecer o nosso aluno para melhorar práticas e métodos para que assim como diz a BNCC aplicar melhores metodologias e valorizar conhecimentos.

\subsection{Pandemia, relações escolares e avaliação escolar}

Falaremos um pouco mais sobre avaliação só que agora tendo em vista o momento atual de 2021, aulas remotas devido à pandemia. O parecer do Conselho Nacional de Educação, ${ }^{\circ} 5$, de 28 de abril de 2020, em seu relato inicial traz o contexto em que as aulas remotas se iniciaram

A OMS declarou, em 11 de março de 2020, que a disseminação comunitária da COVID-19 em todos os Continentes a caracteriza como pandemia. Para contê-la, a OMS recomenda três ações básicas: isolamento e tratamento dos casos identificados, testes massivos e distanciamento social (Conselho Nacional de Educação, 2020b, p. 1).

Assim, devido a iniciativas de isolamento e distanciamento social, as aulas começaram a ser realizadas remotamente em todos os níveis da educação brasileira. Desse cenário Martins e Almeida (2020, p. 221) dizem que "[...] no momento atual é a transposição didática emergencial da educação presencial tradicional para as redes".

Em relação ao ensino remoto as questões iniciais envolviam entender as relações familiares do aluno, já que todos estavam juntos nesse momento. Observou-se que $57,1 \%$ dos alunos dizem que sua família muito contribuiu para com seus estudos em casa enquanto $37,7 \%$ a família pouco colaborou, para outros $7,1 \%$ a família em nada auxiliou. Por consequência desse novo modelo de ensino $92,9 \%$ dos alunos sentem que foram muito prejudicados de alguma forma.

Outro problema que afetou muitos alunos foi às novas demandas que apareceram dentro de casa. Metade dos alunos participantes em algum momento teve que estar deixando de estudar para se dedicarem a ajuda sua família, o que antes não teriam que estar fazendo, influenciando no alto índice de alunos que se sentem prejudicados durante o ensino remoto.

Mesmo com a reformulação do ensino, as atividades continuaram normalmente através de aplicativos e ferramentas tecnológicas chamadas de TICs. Toda essa mudança segundo Martins e Almeida (2020) não se fez rapidamente ou do dia para a noite. Para $85,7 \%$ dos alunos as avaliações escolares pouco ajudaram ou não ajudaram nesse momento.

Ainda no âmbito das avaliações escolares e familiares, 35,7\% dos alunos afirmam que a família não os auxilia em nada nas avaliações, para a metade a sua família pouco ajuda nas avaliações escolares e para 14,3\% a família o auxilia muito em suas avaliações. E neste momento percebemos que durante esse período os alunos estão contando mais com o apoio das TICs e de seus colegas de classe. Pois, $93 \%$ deles afirmaram consultar a internet para realizar atividades e $43 \%$ também consultam os colegas.

Outro fator levantado na pesquisa foi à necessidade dos alunos terem mais contato com o professor em aulas síncronas ou gravadas. Na escola em que foi feita a pesquisa as atividades são feitas da seguinte forma: a escola faz uso da plataforma Conexão Escola, que é conectada a plataforma Google Classroom, e as atividades a serem desenvolvidas são fornecidas pelo Governo de Minas Gerais, por meio da Secretaria Estadual de Educação. Todas as atividades são assíncronas com poucos momentos de aulas feitas simultaneamente. 
Para 92,9\% dos alunos a presença do professor no ensino do conteúdo faz diferença para a sua educação escolar. E por consequência quando questionados sobre se a forma adotada pela escola poderia ser diferente, $57,1 \%$ disseram que sim. Algumas das formas diferentes pedidas pelos alunos foram:

Aluno A: "Eu acho que os professores deveriam tentar fazer os alunos entenderem a matéria, só jogam as atividades nos aplicativos e é só isso que temos, não gravam vídeos explicando a matéria. Poderiam ter mais dinâmica com os alunos".

Aluno F: "atrás de aulas online feitas pelos próprios professores".

Aluno G: "Ter mais aulas on-line específicas de cada matéria”.

Através desses relatos percebe-se que durante o ensino remoto e a grande responsabilidade, os alunos ainda necessitam do apoio e orientação do professor durante as atividades que realizam. Deste modo quando Pavanello e Nogueira (2006, p. 38) dizem que "[...] o professor não pode assumir uma postura passiva; ao contrário, deve dialogar com os alunos para melhor compreender seus processos de pensamento e intervir quando necessário", sendo assim o aluno não consegue de forma autônoma buscar ainda todas as informações que ele necessita, precisando de um intermediador para a construção ativa de seus conhecimentos e habilidades.

E por esse motivo a BNCC nos diz que "para além da necessidade de universalizar o atendimento, outros grandes desafios do Ensino Médio na atualidade são garantir a permanência e as aprendizagens dos estudantes, respondendo às suas aspirações presentes e futuras" (MEC, 2017, p. 461).

\section{Conclusão}

O processo avaliativo envolve muitas variáveis quando olhado pelo lado dos alunos, pois o momento de transformação que a educação vive está modelando novos olhares em relação às necessidades deles. Mais do que estabelecer metas de desempenho para os alunos, observa-se que neste momento precisa-se de intermediadores de conhecimento que caminhem com os alunos, pois serão esses os primeiros contatos com o mundo que serão trabalhados habilidades e desenvolvimento pessoal.

Além disso, a avaliação escolar abre espaços de discussão de diversas formas e caminhos, logo abordando a visão do aluno, percebe-se que esse momento é algo importante. Observou-se que mesmo em alguns momentos, nos quais não sentem seu conhecimento ser valorizado, considerou-se que esse processo os auxilia em seu crescimento. Muitas vezes o modo como à avaliação é aplicada por seus professores pode ou não agradar. Ainda meio que limitado a poucos alunos, outras formas mais livres de ser avaliado por questões de criatividade e participação apareceram presentes na vida escolar de alguns.

Assim, percebe-se que esse momento na escola é usado pelos estudantes como uma forma de obter respostas sobre seus conhecimentos sobe o olhar de seu professor. Como também, mostrar como está seu desempenho e descobrir quais são seus pontos fortes e fracos, como melhorar cada dia mais e buscar novas metas.

Durante a pandemia os alunos se sentiram prejudicados, mas a contribuição da família foi muito importante para a continuação dos estudos. Apesar de em algum momento durante os estudos remotos tivessem de estar abdicando desse momento para ajudar em casa. Destaca-se a necessidade dos alunos de terem um contato mais próximo do professor com aulas e explicações.

Desta forma, a avaliação escolar pode mostrar para aqueles que a usam, os problemas, as dificuldades e futuros desafios. Os alunos ao longo da caminhada escolar e durante as avaliações descobrem e aperfeiçoam suas habilidades e 
estratégias. Podem em momentos de reflexão dos resultados priorizarem ou não determinadas disciplinas, como relacionar seus conhecimentos e fazer bom uso das avaliações para mostrar suas capacidades e anseios perante a sociedade.

\section{Referências}

Brasil (2017). Ministério da Educação. Base Nacional Comum Curricular. Brasília, DF. http://basenacionalcomum.mec.gov.br/images/BNC C_EI_EF_110518_versaofinal_site.pdf

Conselho Nacional de Educação (2020a). Ministério da Educação. Parecer n ${ }^{\circ}$ 19, de 08 de dezembro de 2020. Reexame do Parecer CNE/CP n ${ }^{\circ} 15$, de 6 de outubro de 2020. Diário Oficial. http://portal.mec.gov.br/index.php?option=com_docman\&view=download\&alias=167131-pcp019-20\&category_slug= dezembro-2020 - pdf \&Itemid=30192

Conselho Nacional de Educação (2020b). Ministério da Educação. Parecer n ${ }^{\circ}$ 5/2020, de 28 de abril de 2020. Reorganização do Calendário Escolar. http://portal.mec.gov.br/index.php?option=com_docman\&view=download\&alias=145011-pcp005-20\&category_slug=marco-2020-pdf\&Itemid=301 92

Decreto Legislativo n. 6, de março de 2020 (2020). Diário Oficial da União. Brasilia, DF, 20 de março de 2020. https://pesquisa.in.gov.br/imprensa/jsp/visualiza/index.jsp?data=20/03/2020\&jornal=602\&pagina=1

Fachineto, S., Scantamburlo, E. L. R., Zangalli, L. C., \& Kohnlein, J. T. C. (2020). Avaliação de aprendizagem em meio a pandemia do coronavírus no Brasil. Anuário Pesquisa e Extensão Unoesc São Miguel do Oeste, 5, e24090-e24090.https://unoesc.emnuvens.com.br/apeusmo/article/view/25090/14758

Furlan, M. I. C. (2007). Avaliação da aprendizagem escolar: convergências e divergências. Annablume.

Hoffmann, J. (2001). Avaliar para promover: as setas do caminho. Ed. Mediação.

Hoffmann, J. (1993) Avaliação mediadora: uma prática em construção da pré-escola à universidade. Porto Alegre: Educação \& Realidade.

Libâneo, J. C. (2006). Didática. Cortez.

Libâneo, J. C. (1983). Tendências pedagógicas na prática escolar. Revista da Associação Nacional de Educação-ANDE, 3, 11-19.

Luckesi, C. C. (2014). Sobre notas escolares: distorções e possibilidades. São Paulo: Cortez.

Luckesi, C. C. (2011). Avaliação da aprendizagem escolar: estudos e proposições. (22. ed.). Cortez.

Luckesi, C. C. (2005). Avaliação da aprendizagem escolar: estudos e proposições (17 ed.). Cortez.

Martins, V., \& Almeida, J. (2020). Educação em Tempos de Pandemia no Brasil: Saberesfazeres escolares em exposição nas redes. Revista Docência e Cibercultura, 4(2), 215-224. https://www.e-publicacoes.uerj.br/index.php/re-doc/article/view/51026/34672

Moraes, S. P. G. de, \& Moura, M. O. de (2009). Avaliação do Processo de Ensino e Aprendizagem em Matemática: contribuições da teoria históricocultural. Boletim de Educação Matemática, 22(33), 97-116. https://www.redalyc.org/pdf/2912/291221900006.pdf

Pavanello, R. M., \& Nogueira, C. M. I. (2006). Avaliação em Matemática: algumas considerações. Estudos em avaliação educacional, 17(33), 29-42. http://publicacoes.fcc.org.br/index.php/eae/article/view/2125/2082

Perrenoud, P; Thurler, M. G. As competências para ensinar no século XXI: a formação dos professores e o desafio da avaliação. Artmed Editora, 2009.

Pestana, D. M. A., \& Coqui, A. D. (2021). Novos contextos pedem novas posturas: a avaliação em tempos de pandemia. Revista Amor Mundi, 2(1), 41-49. http://journal.editorametrics.com.br/index.php/am ormundi/article/view/36/40

Rampazzo, S. D. R., \& Jesus, A. D. (2011). Instrumentos de avaliação: reflexões e possibilidades de uso no processo de ensino e aprendizagem. Londrina. Produção Didático-Pedagógica apresentada ao Programa de Desenvolvimento Educacional. NRE. 2011, 24f. http://www.dma.ufv.br/downloads/MAT\%20103/2019-II/textos/INSTRUMENTOS\%20DE\%20AVALIACAO\%20-\%20MAT\%20103\%20-\%202019-II.pdf

Zabala, A. (1998). A prática educativa: como ensinar. Artmed, 224. cap. 8 